\title{
Surgical patient outcomes after the increased use of bilateral lung transplantation
}

Andrew C. Chang, MD, ${ }^{a}$ Kevin M. Chan, MD, ${ }^{b}$ Robert J. Lonigro, MS, ${ }^{c}$ Christine L. Lau, MD, ${ }^{a}$ Vibha N. Lama, MD, Kevin R. Flaherty, MD, MS, ${ }^{b}$ Ros Florn, RN, ${ }^{b}$ Allan Pickens, MD, ${ }^{a}$ Susan Murray, ScD, ${ }^{c}$ Fernando J. Martinez, MD, MS, and Mark B. Orringer, $\mathrm{MD}^{\mathrm{a}}$

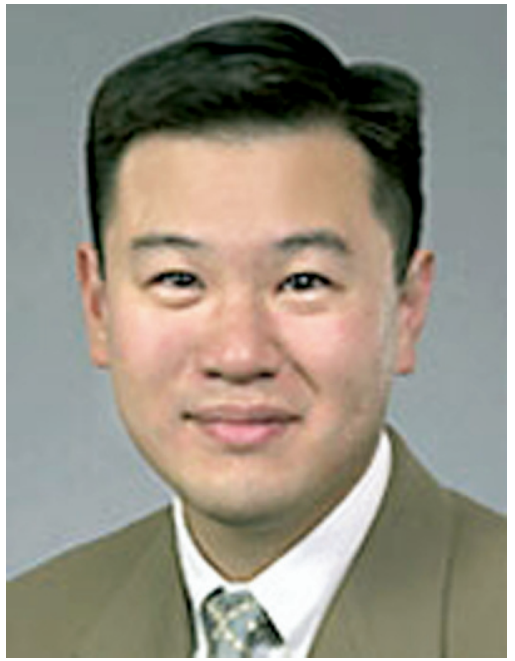

Dr Chang
From the Section of Thoracic Surgery, ${ }^{\mathrm{a}} \mathrm{Di}$ vision of Pulmonary and Critical Care Medicine, ${ }^{\mathrm{b}}$ and Department of Biostatistics, ${ }^{c}$ University of Michigan Health System, Ann Arbor, Mich.

Read at the Eighty-sixth Annual Meeting of The American Association for Thoracic Surgery, Philadelphia, Pa, April 29-May 3, 2006.

Received for publication April 28, 2006; revisions received Sept 3, 2006; accepted for publication Sept 26, 2006.

Address for reprints: Andrew C. Chang, MD, Section of Thorracic Surgery, University of Michigan, TC2120G/0344, 1500 East Medical Center Dr, Ann Arbor, MI 48109 (E-mail: andrwchg@umich.edu).

J Thorac Cardiovasc Surg 2007;133:532-40

$0022-5223 / \$ 32.00$

Copyright (C) 2007 by The American Association for Thoracic Surgery

doi:10.1016/j.jtcvs.2006.09.060
Objectives: Despite the potential limitation of organ availability, several surgical groups have advocated preferential bilateral lung transplantation because of its demonstrated long-term survival advantage. Comparative results for single and sequential double lung transplantation performed at a single center are evaluated to determine whether such a policy improves patient outcome.

Methods: A retrospective analysis of demographic and outcome data for patients undergoing lung transplantation was performed. Patients were grouped as single or double lung recipients and segregated into diagnostic categories according to the lung allocation scoring system. Era terciles were chosen on the basis of year of transplant, operating surgeon, and transplant volume.

Results: Between November 1990 and September 2005, 344 lung transplant procedures were performed in 339 patients. Over three time periods evaluated, the proportion of patients undergoing double lung transplant procedures increased. Overall survivals at 3 months and 1, 3, and 5 years were 89\%, 79\%, 60\%, and 52\%, respectively. After adjusting for lung recipient characteristics, survival after double lung transplantation was improved when compared with single lung transplantation $(P=.020)$. Overall patient survival among the three time periods was not significantly different at 30 days and 1 and 3 years despite increasing maximal donor organ ischemia times.

Conclusions: In this single-center study, despite longer median allograft ischemic times, as well as greater patient acuity as determined by listing diagnosis, overall early and midterm patient survival has remained higher than nationally reported figures. Bilateral lung transplantation in eligible patients is the procedure of choice.

$\mathrm{P}$ ulmonary transplantation has been established as an effective treatment option for selected patients with end-stage lung disease. Broad application of this therapy is hampered primarily by the limited availability of suitable donor organs. Application of "extended" donor criteria, ${ }^{1,2}$ government-led initiatives to increase public awareness of the need for organ donation, and, more recently, development of protocols for living-related lobar transplantation or for lung donation after cardiac death all may increase the number of available organs for transplantation. ${ }^{3}$ Evaluation of international registry data has demonstrated consistently that survival is greater after bilateral lung transplantation than single lung transplantation, although this difference appears to depend on a variety of factors, including the age of the recipient and etiology of end-stage lung disease. ${ }^{4}$

The purpose of this retrospective study is to evaluate our single-center experience of pulmonary transplantation and particularly the impact of bilateral organ transplantation. We report both overall and disease-dependent survival as well as reasons for hospital mortality. 


\author{
Abbreviations and Acronyms \\ $\mathrm{CI}=$ confidence interval \\ $\mathrm{HR}=$ hazard ratio \\ ISHLT $=$ International Society of Heart and Lung \\ Transplantation \\ SRTR $=$ Scientific Registry of Transplant Recipients
}

\section{Materials and Methods Patients}

All adult lung transplants performed at the University of Michigan, Ann Arbor, between November 1990 and September 2005 were included in this review. Nine patients who received heart-lung transplantation at our institution were excluded. Retrospective analyses of both transplant records and a computerized database were performed. Approval for this study, including waiver of informed consent, was obtained from the University of Michigan Institutional Review Boards. Recipient diagnoses were reviewed and classified into four groups: group A, obstructive lung diseases; group B, pulmonary hypertensive disorders; group $\mathrm{C}$, bronchiectatic diseases including cystic fibrosis; and group D, pulmonary fibrotic diseases, as designated by the lung allocation scoring system. ${ }^{5}$ Recipient selection was in accordance with guidelines established by the International Society of Heart and Lung Transplantation (ISHLT) and the American Thoracic Society. ${ }^{6}$ In our initial analysis, patients were segregated by year of transplantation and operating surgeon into terciles ranging from 1990-1995, 19962000, and 2001-2005.

\section{Donor Factors}

We adhered to general selection criteria for selection of suitable cadaveric donor organs. ${ }^{1,2}$ No patients received either livingrelated lung transplant or organs obtained from non-heart beating donors. Pulmoplegia consisted of Euro-Collins solution until 1998 and University of Wisconsin solution thereafter.

\section{Recipient Procedure}

Before anesthetic induction, the majority of our patients had epidural catheters placed. Operative technique varied with the operating surgeon. Generally, single lung transplantation was performed via posterolateral thoracotomy. Bilateral lung transplantation was performed via bilateral sequential posterolateral thoracotomy or via bilateral anterolateral thoracotomy with or without transverse sternotomy. Selective use of inhaled nitric oxide intraoperatively and postoperatively and intraoperative cardiopulmonary bypass was used for patients with pulmonary hypertension or hypoxemia. For bilateral lung transplantation, total ischemic time indicated time to reperfusion of the second lung. During this study period, perioperative cytolytic antibody therapy was not administered.

\section{Infection Prophylaxis}

Perioperative antibacterial agents consisted of vancomycin and ceftazidime for the first 48 hours after transplant and was adjusted according to intraoperative bronchial cultures. Patients at risk for cytomegalovirus infection were treated with postoperative ganci- clovir for 21 days. Pneumocystis carinii prophylaxis was achieved with trimethoprim/sulfamethoxazole or dapsone.

\section{Immunosuppression}

Patients received preoperative oral cyclosporine $(5 \mathrm{mg} / \mathrm{kg})$. Postoperatively, intravenous cyclosporine was administered, beginning at $3 \mathrm{mg} / \mathrm{h}$, and the infusion rate was adjusted to maintain serum cyclosporine levels at 200 to $250 \mathrm{ng} / \mathrm{mL}$. Patients were transitioned to lipid-emulsified cyclosporine (Neoral; Novartis Pharmaceuticals Corporation, East Hannover, NJ). Azathioprine therapy was initiated in the immediate postoperative period, $2 \mathrm{mg} / \mathrm{kg}$ intravenously/ orally daily, adjusting doses for leukopenia (white blood cell count $<3500 / \mathrm{mm}^{3}$ ). Patients received $1000 \mathrm{mg}$ methylprednisolone intravenously intraoperatively at organ reperfusion and then tapered $10 \%$ per day from $100 \mathrm{mg}$ intravenously/orally twice daily to 20 $\mathrm{mg} /$ day.

\section{Statistical Analysis}

Hospital mortality was defined as in-hospital death at initial hospitalization for transplantation. Continuous data were compared between groups by the 2-sample $t$ test. Categorical data were analyzed by $\chi^{2}$ tests or, alternatively, by the Fisher exact tests for comparisons with small expected cell counts. Multivariate survival analysis was performed with the Cox regression method. ${ }^{7}$

\section{Results}

\section{Patient Characteristics}

Between 1995 and 2005, 459 patients were listed for transplantation at the University of Michigan (Figure 1). Within each year of listing, on average, $57.6 \% \pm 6.4 \%$ of patients listed went on to transplantation whereas $26.1 \% \pm$ $10.0 \%$ of patients died. The median waiting list time for patients undergoing transplantation since 1995 was 7.3 months (range 3.5-27.2 months).

Between November 1990 and September 2005, a total of 339 patients underwent 344 transplant operations, including 5 patients undergoing retransplantation, with annual distribution and median waiting list time illustrated in Figure 1. The distribution of specific disease processes is detailed in Table 1. Of 249 patients in group A, 37 were diagnosed with $\alpha_{1}$-antitrypsin deficiency. The sex distributions of the single and double lung transplant patient populations were similar, but the single transplant recipients tended to be older $(53.8$ years vs 44.7 years; $P<.001$ ).

Proportionately more patients in diagnosis group A received single versus double lung transplants compared with the other diagnosis groups. The relative proportion of double lung transplants varied significantly across 5-year time periods, with the 1996-2000 era dominated by single lung transplants, and a substantial increase in double lung transplants more recently from 2001 to 2005 . The average ischemic time for double transplants was significantly greater than that for single transplants (418 vs 233 minutes; $P<$ .001). Accordingly, median graft ischemia times increased 


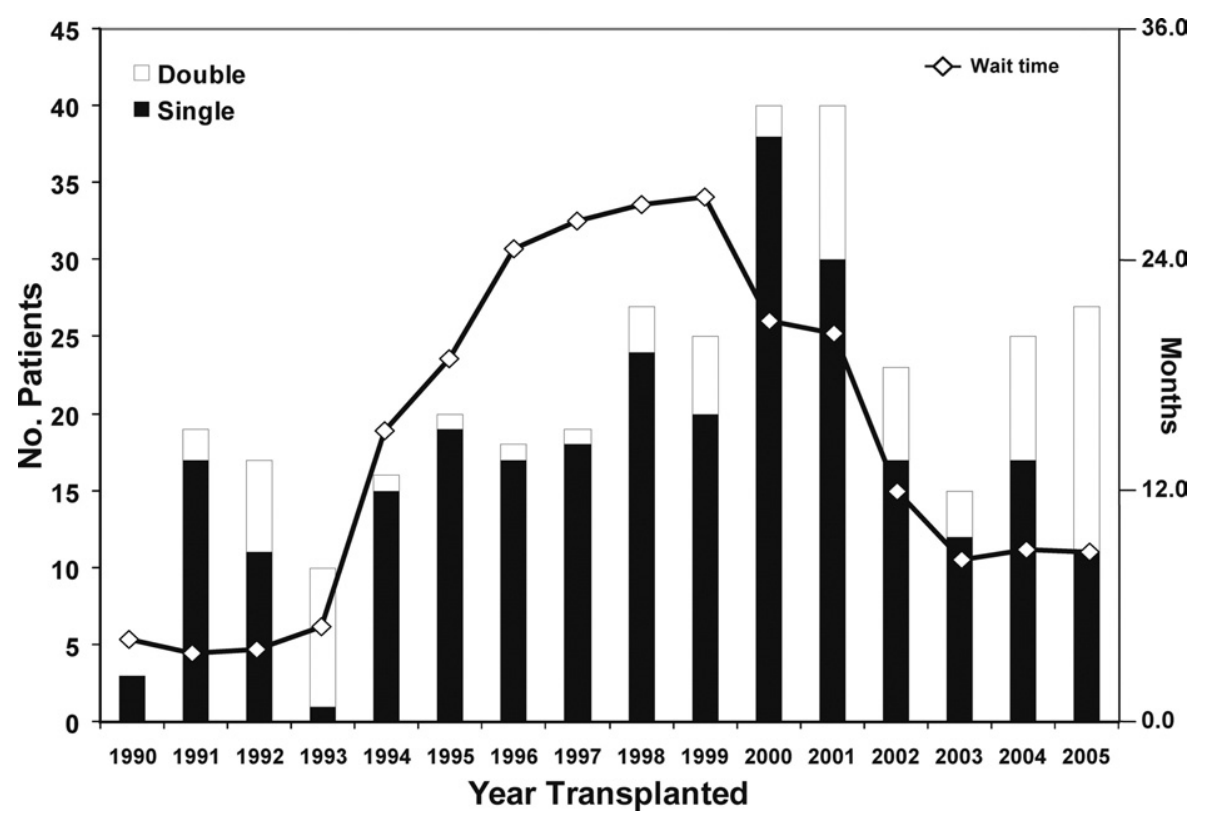

Figure 1. Number and type of lung transplant performed and median waiting list times (months) annually.

over our three eras of transplantation from 218 minutes to 231 and 285 minutes $(P<.001)$.

\section{Survival and Hospital Mortality}

Hospital mortality occurred in 34 patients (10\%) and was greatest $(33 \%)$ for patients with pulmonary hypertensive disorders (group B), including 1 patient with Eisenmenger syndrome and 4 with primary pulmonary hypertension (Table 2). In contrast, there were no in-hospital deaths for patients with cystic fibrosis or immune deficiency (group C). Primary graft dysfunction $(\mathrm{n}=12)$, infection $(\mathrm{n}=8)$, and intraoperative complications $(n=4)$ were the chief reasons for in-hospital mortality. Two deaths each were due to bronchial anastomotic disruption, late respiratory failure, and complications resulting from gastrointestinal perforation. Deaths were attributed to acute rejection, myocardial ischemia, stroke, and tension pneumothorax in 1 patient each.

\section{Retransplantation}

Five patients underwent single lung retransplantation (Table 3). In our early experience, 3 patients received ipsilateral retransplant for primary graft dysfunction, with 2 patients dying in the hospital or in the operating room. Having been listed urgently, each of these patients was on the waiting list for less than 1 week. An additional 2 patients subsequently underwent elective retransplantation for bronchiolitis obliterans syndrome and are ongoing survivors.

\section{Multivariate Analysis}

The overall 3-month and 1-, 3-, and 5-year survivals (95\% confidence intervals $[\mathrm{CI}]$ ) for the average study participant

TABLE 1. Baseline characteristics, lung transplant patients $(n=339)$

\begin{tabular}{lccc}
\hline & Single $(\mathbf{n}=\mathbf{2 6 5})$ & Double $(\mathbf{n}=\mathbf{7 4 )}$ & $\boldsymbol{P}$ value* \\
\hline Gender (M/F) & $129 / 136$ & $35 / 39$ & $P=.937$ \\
Mean age at aransplant (y) & $53.8(\mathrm{SD}=8.16)$ & $44.7(\mathrm{SD}=9.42)$ & $P<.001$ \\
Mean ischemia time (min) & $233(\mathrm{SD}=74)$ & $418(\mathrm{SD}=70)$ & $P<.001$ \\
Diagnosis group A $(\mathrm{n}=249)$ & $206(82.7 \%)$ & $43(17.3 \%)$ & $P=.002$ \\
Diagnosis group B (n=15) & $10(66.7 \%)$ & $5(33.3 \%)$ & $P=.334$ \\
Diagnosis group C (n=16) & $0(0.0 \%)$ & $16(100.0 \%)$ & $P<.001$ \\
Diagnosis group D (n=59) & $49(83.1 \%)$ & $10(16.9 \%)$ & $P=.387$ \\
Transplant years 1990-1995 & $63(76.8 \%)$ & $12(9.3 \%)$ & $P=.760$ \\
Transplant years 1996-2000 & $117(90.7 \%)$ & $43(33.6 \%)$ & $P<.001$ \\
Transplant years 2001-2005 & $85(66.4 \%)$ & $P<.001$ & \\
\hline
\end{tabular}

$* P$ values correspond to the Fisher exact test for categorical variables and $t$ test for continuous variables. $P$ values for diagnosis and year categories compare the proportion of single/double transplants in each category with all others. 
TABLE 2. Hospital mortality

\begin{tabular}{lc}
\hline Overall & $\mathbf{3 4 / 3 3 9 ( 1 0 . 0 \% )}$ \\
\hline Era & \\
$1990-1995$ & $9 / 82(11.0 \%)$ \\
$1996-2000$ & $16 / 129(12.4 \%)$ \\
$2001-2005$ & $9 / 128(7.0 \%)$ \\
Diagnosis group & \\
A & $23 / 249(9.2 \%)$ \\
B & $5 / 15(33.3 \%)$ \\
C & $0 / 16$ \\
D & $6 / 59(10.2 \%)$ \\
\hline
\end{tabular}

were $0.89(0.86,0.93), 0.79(0.75,0.84), 0.60(0.55,0.66)$, and $0.52(0.46,0.59)$ (Figure $2, A)$. Results from the multivariate Cox model (Table 4, Figure 2, B) indicated that after adjusting for diagnosis, sex, time of transplant, and age at transplant, double lung transplant patients had significantly improved survival over single transplant patients, with a hazard ratio (HR) of 0.583 (95\% CI, 0.371, 0.917; $P=.020$ ). This survival advantage was not altered by including or excluding the 16 patients in group $\mathrm{C}$ undergoing bilateral transplantation. We observed marginally significant improved survival for group A with bilateral lung transplantation when compared with single lung transplantation (HR 0.617, 95\% CI 0.368,1.034; $P=.067$ ).

Of the 4 diagnosis groups (Figure 2, C), after adjusting for transplant type, sex, time of transplant, and age, patients in diagnosis group B experienced the worst survival, with an HR of 3.365 as compared with patients in diagnosis group A (95\% CI 1.685, 6.720; $P=.001)$.

Sex, year of transplant, and age at transplant were not statistically significant in our analysis. Interactions between type of transplant and these other variables were also explored, but no statistically significant interactions were discovered, although power for assessing interactions was limited. In the subset of 288 patients with known ischemic times, no relationship to posttransplant survival was observed (HR 1.005, 95\% CI 0.874, 1.160; $P=.94)$.

\section{Discussion}

The use of pulmonary transplantation for patients with end-stage lung disease has changed dramatically as a result of advances in donor management, organ procurement, operative approach, and perioperative treatment. Our transplantation program, initiated in 1990, has benefited from the surgical outcomes and analyses reported by several large centers. ${ }^{8-11}$ Our outcomes likely reflect patient selection, with the large majority of our patients undergoing transplantation for obstructive lung diseases $(249 / 339,73.4 \%)$. Patients with restrictive lung diseases $(59 / 339,17.4 \%)$ constituted the next largest group.

As reported in several single-center studies and in the ISHLT registry, we observed that patients with pulmonary hypertensive disorders at our institution had significantly worse outcomes than our entire cohort. Although in our current practice such patients will undergo bilateral lung transplantation, early in our experience we elected to perform single lung transplantation for this group, since early data did not indicate any survival advantage favoring bilateral transplantation. ${ }^{12}$ We did not discern any difference in hospital mortality between single and bilateral lung transplant recipients for the 15 patients in group B, nor did we observe any significant differences in overall survival attributable to listing diagnosis, likely reflecting the smaller cohorts of patients for diagnostic groups other than patients with obstructive lung disease.

Patients undergoing bilateral sequential pulmonary transplantation had significantly improved overall survival compared with those receiving single lung transplantation, even when adjusting for age at transplantation and listing diagnosis group. Notably, we observed no hospital mortality among patients with cystic fibrosis or immune deficiencyrelated lung diseases (group C), for which only bilateral lung transplantation was offered. Current data suggest that

TABLE 3. Baseline characteristics and survival times for the 5 patients requiring retransplant

\begin{tabular}{|c|c|c|c|c|c|c|c|c|}
\hline Patient & Sex & TX type & Diagnosis & Waiting time (d) & Graft survival (d) & Ischemia (h) & Year of TX & Age at TX (y) \\
\hline \multirow[t]{2}{*}{1} & $\mathrm{M}$ & Single (L) & $\mathrm{PF}$ & 7 & $37^{*}$ & N/A & 1991 & 37 \\
\hline & & Single (L) & & 1 & $5310^{*}$ & $\mathrm{~N} / \mathrm{A}$ & 1991 & 37 \\
\hline \multirow[t]{2}{*}{2} & $\mathrm{~F}$ & Single $(R)$ & COPD & 2 & $193^{*}$ & $\mathrm{~N} / \mathrm{A}$ & 1991 & 57 \\
\hline & & Single $(R)$ & & 6 & 29 & $\mathrm{~N} / \mathrm{A}$ & 1991 & 57 \\
\hline \multirow[t]{2}{*}{3} & $\mathrm{M}$ & Single (L) & $\mathrm{PF}$ & 205 & $8^{*}$ & $4: 41$ & 1994 & 46 \\
\hline & & Single (L) & & 1 & 0 & $\mathrm{~N} / \mathrm{A}$ & 1994 & 46 \\
\hline \multirow[t]{2}{*}{4} & $\mathrm{M}$ & Single (L) & PF & 357 & $2002^{*}$ & $4: 25$ & 1996 & 30 \\
\hline & & Single $(R)$ & & 1200 & $1204^{*}$ & $3: 57$ & 2002 & 35 \\
\hline \multirow[t]{2}{*}{5} & $\mathrm{M}$ & Single $(R)$ & $\mathrm{PF}$ & 363 & $640^{*}$ & $6: 25$ & 2002 & 57 \\
\hline & & Single $(R)$ & & 93 & $564^{*}$ & $4: 42$ & 2004 & 59 \\
\hline
\end{tabular}

$T X$, Transplant; $L$, left; $R$, right; $P F$, pulmonary fibrosis; $C O P D$, chronic obstructive pulmonary disease. *Patient was still alive at the end of this time period. 

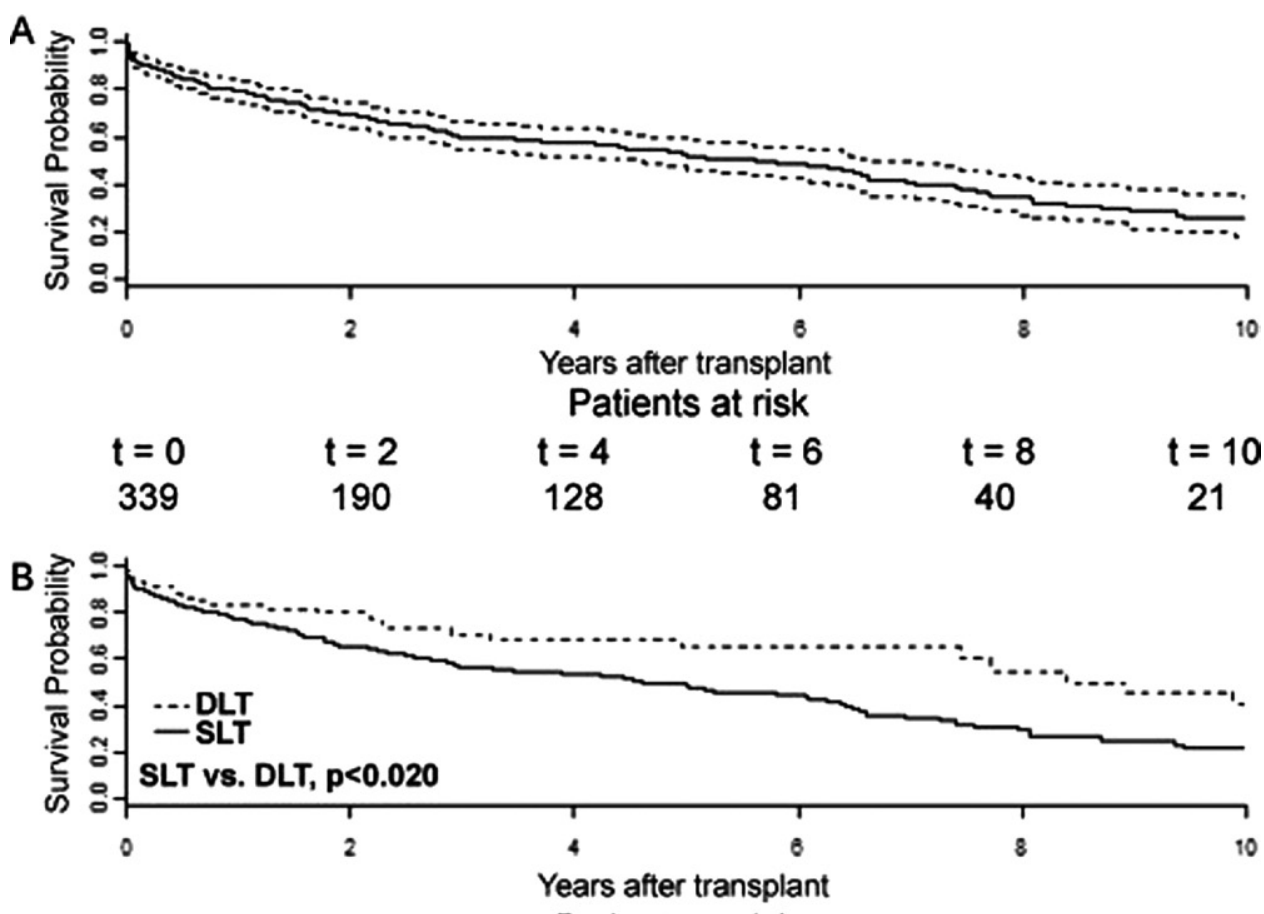

Patients at risk

$\begin{array}{lcccccc} & t=0 & t=2 & t=4 & t=6 & t=8 & t=10 \\ \text { SLT } & 265 & 152 & 103 & 61 & 27 & 12 \\ \text { DLT } & 74 & 38 & 25 & 20 & 13 & 9\end{array}$

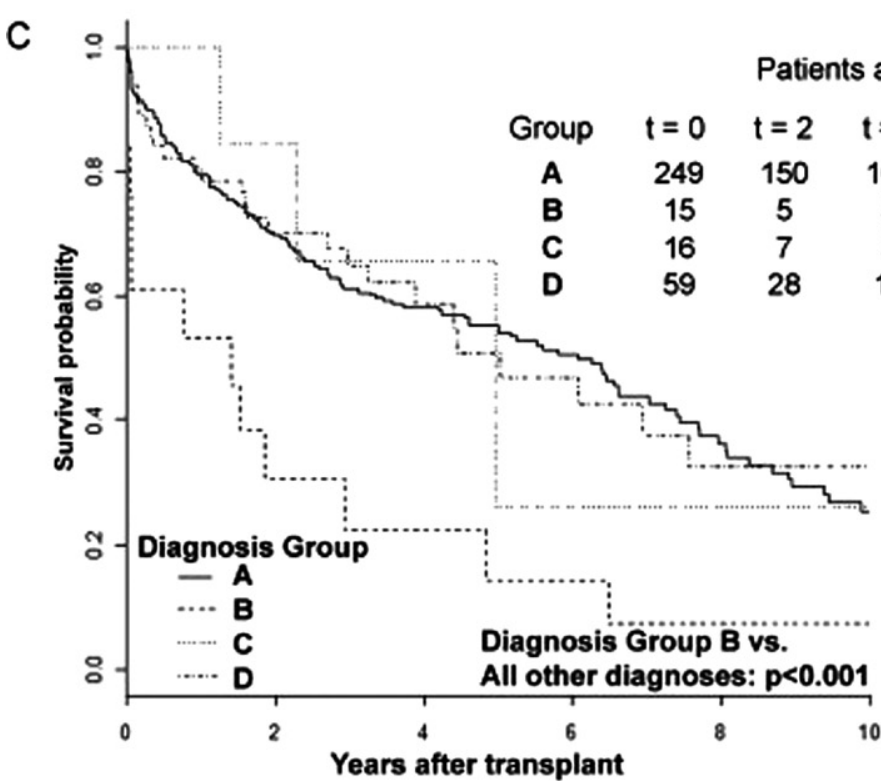

Figure 2. A, Overall survival for 339 patients undergoing lung transplantation at the University of Michigan between November 1990 and September 2005. Cox multivariate survival, with 95\% confidence limits (dotted lines), adjusted for transplant type, recipient sex, age, year of transplantation, and listing diagnosis. B, Cox multivariate survival by bilateral (DLT) or single lung transplantation (SLT), adjusted for recipient sex, age, year, and diagnosis at transplantation. C, Cox multivariate survival by listing diagnosis, adjusted for transplant type, recipient sex, age, and year at transplantation. 
TABLE 4. Multivariate Cox survival model for 339 lung transplant recipients

\begin{tabular}{llcc}
\hline Variable & HR & $\mathbf{9 5 \%}$ CI for HR & $P$ value (HR = 1) \\
\hline Type of transplant (double vs single) & 0.583 & $(0.371,0.917)$ & $P=.020$ \\
Diagnosis group A & 1.000 & REF & REF \\
Diagnosis group B (compared with A) & 3.365 & $(1.685,6.720)$ & .001 \\
Diagnosis group C (compared with A) & 0.828 & $(0.231,2.964)$ & $P=.772$ \\
Diagnosis group D (compared with A) & 1.026 & $(0.669,1.571)$ & $P=.908$ \\
Sex (M vs F) & 0.962 & $(0.710,1.303)$ & $P=.803$ \\
Time of transplant (y since 1990) & 1.017 & $(0.972,1.063)$ & $P=.473$ \\
Age at transplant (y) & 1.009 & $(0.988,1.031)$ & $P=.380$ \\
\hline
\end{tabular}

$H R$, Hazard ratio; $C l$, confidence interval; $R E F$, reference.

Burkholderia cepacia genomovar subtypes are important in determining transplant outcomes. ${ }^{13}$ In the past, colonization with $B$ cepacia had been associated with poorer outcomes after transplantation ${ }^{14}$ and was therefore considered a contraindication to listing in our population during the period of the study.

There is considerable debate regarding the utility of pulmonary transplantation in the treatment of chronic obstructive pulmonary disease. Our data are consistent with registry data and single-center experiences ${ }^{15,16}$ that have demonstrated significantly improved survival for patients with obstructive lung diseases undergoing bilateral rather than single lung transplantation. In an analysis using registry data, Hosenpud and associates ${ }^{17}$ demonstrated that although patients undergoing transplantation for interstitial pulmonary fibrosis and cystic fibrosis obtained a benefit in overall survival when compared with waiting list survival, the predicted waiting list survival for patients with chronic obstructive pulmonary disease, up to the 2-year period of follow-up in the study, exceeded posttransplantation survival. These authors cautioned, however, that non-survival related benefits, particularly posttransplantation quality of life, could not be accounted for in their analysis. We did not determine whether spirometry or exercise tolerance improved significantly in bilateral lung recipients, as has been demonstrated by others. ${ }^{18}$

With the implementation in May 2005 of the lung allocation score system, ${ }^{19}$ donor organ allocation in the United States is currently assigned on the basis of estimated pretransplant mortality and postoperative survival, with the goal of developing a regional need-based system, rather than relying on waiting list time accrual. With more urgent patients undergoing transplantation, we may see a slight increase in posttransplant morbidity and mortality in our patient population, but also a reduction in deaths on the lung waiting list. The Scientific Registry of Transplant Recipients (SRTR) has developed a thoracic simulated allocation model that potentially can provide further insight, using nationally collected data, regarding the impact on waiting list mortality of performing bilateral lung transplantation more frequently. It remains to be seen whether our patients with obstructive lung disease will receive organ offers at a rate similar to our past experience since these patients will have less urgency than patients with other lung diagnoses when ordered according to the lung allocation score.

Of interest, we observed that in our limited experience with retransplantation, as has been reported elsewhere, patients with acute graft dysfunction fared poorly. ${ }^{20,21} \mathrm{How}-$ ever, the 2 patients with pulmonary fibrosis undergoing retransplantation for chronic rejection have been able to achieve survival approaching that of their initial organ transplantation. Given that several studies have argued that overall survival does not appear to differ ${ }^{22}$ and may actually be worse ${ }^{23}$ with bilateral rather than single lung transplantation, particularly for patients with restrictive lung diseases, it remains unknown whether sequential unilateral transplantation rather than bilateral lung transplantation should be offered, especially in the context of the current lung allocation score.

\section{Conclusions}

As we and others have demonstrated, acceptable patient survival after pulmonary transplantation is consistent and reproducible across institutions and diagnoses. Since the first lung transplant in June 1963 by Dr James Hardy, ${ }^{24}$ with continued re-evaluation using both registry data and individual institutional experiences over the past several decades, both operative technique and perioperative management after lung transplantation have evolved and improved. Now with measures being initiated to provide more equitable organ allocation, it becomes imperative to identify factors that predict not only survival but benefits in quality of life. This retrospective study has provided benchmark survival data that will allow our institution and ideally others to engage in ongoing quality assessment and improvement to continue optimizing surgical and long-term outcomes after pulmonary transplantation.

Dr Chang was the primary author and principal investigator of the study; he was responsible for the design of the study, analysis, 
and interpretation of the data. Drs Chan, Lama, and Lau provided input on the study design, interpretation of data, and reviewed and approved the final manuscript. Drs Flaherty and Pickens and Ms Florn provided and cared for study patients and approved the final manuscript. Dr Murray and Mr Lonigro performed the statistical analyses, helped organize the content, and reviewed and approved the final manuscript. Drs Martinez and Orringer supervised the acquisition and interpretation of the data, provided critical input, and approved the final manuscript.

We acknowledge G. Michael Deeb, MD, Mark D. Iannettoni, MD, and Joseph P. Lynch III, MD, for their past contributions to the University of Michigan pulmonary transplantation program, and Ms Jennifer Berry for her ongoing dedication to data collection and database maintenance.

\section{References}

1. Sundaresan S, Semenkovich J, Ochoa L, Richardson G, Trulock E, Cooper J, et al. Successful outcome of lung transplantation is not compromised by the use of marginal donor lungs. J Thorac Cardiovasc Surg. 1995;109:1075-80.

2. Pierre A, Sekine Y, Hutcheon M, Waddell T, Keshavjee S. Marginal donor lungs: a reassessment. J Thorac Cardiovasc Surg. 2002;123: 421-8.

3. Egan TM. Non-heart-beating donors in thoracic transplantation. J Heart Lung Transplant. 2004;23:3-10.

4. Trulock EP, Edwards LB, Taylor DO, Boucek MM, Keck BM, Hertz MI. Registry of the International Society for Heart and Lung Transplantation: Twenty-second official adult lung and heart-lung transplant report-2005. J Heart Lung Transplant. 2005;24:956-67.

5. Murray S, Merion RM, McCullough KP, Bustami RT, Gillespie BW, Wolfe RA, et al. Diagnosis-based models of lung transplant waiting list mortality. Am J Transplant. 2002;2(s3):270 (abstract 524).

6. International guidelines for the selection of lung transplant candidates: The American Society for Transplant Physicians (ASTP)/American Thoracic Society (ATS)/European Respiratory Society (ERS)/International Society for Heart and Lung Transplantation (ISHLT). Am. J. Respir. Crit. Care Med. 1998;158:335-9.

7. Cox DR. Regression models and life-tables. J R Statist Soc B. 1972; 34:187-220.

8. Burton CM, Milman N, Carlsen J, Arendrup H, Eliasen K, Andersen $\mathrm{CB}$, et al. The Copenhagen National Lung Transplant Group: survival after single lung, double lung, and heart-lung transplantation. J Heart Lung Transplant. 2005;24:1834-43.

9. de Perrot M, Chaparro C, McRae K, Waddell TK, Hadjiliadis D, Singer LG, et al. Twenty-year experience of lung transplantation at a single center: influence of recipient diagnosis on long-term survival. J Thorac Cardiovasc Surg. 2004;127:1493-501.

10. Meyers BF, Lynch J, Trulock EP, Guthrie TJ, Cooper JD, Patterson GA. Lung transplantation: a decade of experience. Ann Surg. 1999; 230:362-70.

11. Harringer W, Wiebe K, Struber M, Franke U, Niedermeyer J, Fabel H, et al. Lung transplantation-10-year experience. Eur J Cardiothorac Surg. 1999;16:546-54.

12. Pielsticker EJ, Martinez FJ, Rubenfire M. Lung and heart-lung transplant practice patterns in pulmonary hypertension centers. J Heart Lung Transplant. 2001;20:1297-304.

13. Aris RM, Routh JC, Lipuma JJ, Heath DG, Gilligan PH. Lung transplantation for cystic fibrosis patients with Burkholderia cepacia complex. Survival linked to genomovar type. Am J Respir Crit Care Med. 2001;164:2102-6.

14. Egan TM, Detterbeck FC, Mill MR, Bleiweis MS, Aris R, Paradowski $\mathrm{L}$, et al. Long term results of lung transplantation for cystic fibrosis. Eur J Cardiothorac Surg. 2002;22:602-9.

15. Meyer DM, Bennett LE, Novick RJ, Hosenpud JD. Single vs bilateral, sequential lung transplantation for end-stage emphysema: influence of recipient age on survival and secondary end-points. J Heart Lung Transplant. 2001;20:935-41.

16. Cassivi SD, Meyers BF, Battafarano RJ, Guthrie TJ, Trulock EP, Lynch JP, et al. Thirteen-year experience in lung transplantation for emphysema. Ann Thorac Surg. 2002;74:1663-70.

17. Hosenpud JD, Bennett LE, Keck BM, Edwards EB and Novick RJ. Effect of diagnosis on survival benefit of lung transplantation for end-stage lung disease. Lancet. 1998;351:24-7.

18. Pochettino A, Kotloff RM, Rosengard BR, Arcasoy SM, Blumenthal NP, Kaiser LR, et al. Bilateral versus single lung transplantation for chronic obstructive pulmonary disease: intermediate-term results. Ann Thorac Surg. 2000;70:1813-9.

19. Merion RM, Hulbert-Shearon TE, Bustami RT, Garrity ER, Egan TM, Port FK, et al. Proposed lung allocation system based on medical urgency and transplant benefit. Am J Transplant. 2004;4(s8):414 (abstract 936).

20. Novick RJ, Stitt LW, Al-Kattan K, Klepetko W, Schafers HJ, Duchatelle JP, et al. Pulmonary retransplantation: predictors of graft function and survival in 230 patients. Pulmonary Retransplant Registry. Ann Thorac Surg. 1998;65:227-34.

21. Strueber M, Fischer S, Gottlieb J, Simon AR, Goerler H, Gohrbandt B, et al. Long-term outcome after pulmonary retransplantation. J Thorac Cardiovasc Surg. 2006;132:407-12.

22. Meyers B, Lynch J, Trulock E, Guthrie T, Cooper J, Patterson G. Single versus bilateral lung transplantation for idiopathic pulmonary fibrosis: a ten-year institutional experience. J Thorac Cardiovasc Surg. 2000;120:99-107.

23. Meyer DM, Edwards LB, Torres F, Jessen ME, Novick RJ. Impact of recipient age and procedure type on survival after lung transplantation for pulmonary fibrosis. Ann Thorac Surg. 2005;79:950-7.

24. Hardy JD. The first lung transplant in man (1963) and the first heart transplant in man (1964). Transplant Proc. 1999;31:25-9.

\section{Discussion}

Dr Shaf Keshavjee (Toronto, Ontario, Canada). I congratulate the authors on an excellent collection of their data demonstrating continuously improved outcomes after lung transplantation in their institution.

As you know, we in Toronto also favor bilateral lung transplantation strongly, with $80 \%$ to $90 \%$ of our transplants in our entire program being bilateral lung transplants. In assessing the results of bilateral lung transplantation from Toronto, St Louis, and Duke University, we found a significant functional and survival benefit for bilateral lung transplantation over single lung transplantation in patients with emphysema, but in the other disease categories the difference was less obvious.

In looking at your data, I have trouble reconciling your conclusion with your own experience. You report that $75 \%$ of your patients underwent transplantation for emphysema, yet when you analyzed that group you did not show a significant advantage of bilateral over single lung transplantation. I think your single lung transplant group was significantly disadvantaged in that the single lung transplant patients in your institution were a full decade older. Having very high-risk recipients, that is, a single lung transplant for pulmonary hypertension, also disadvantaged the single lung transplant group. So, your bilateral group had the advantage of those 16 patients with cystic fibrosis who received a bilateral lung transplant and your single lung transplant group had the disadvantage of 15 patients with pulmonary 
hypertension and a 33\% mortality. Did you analyze the bilateral versus single transplant results by excluding that very high-risk group of single lung transplants for pulmonary hypertension?

Dr Chang. Dr Keshavjee, thank you for your comments and insight. First, as an aside, I would like to point out that it has been about 20 years to the day since the Toronto group published the results of their initial experience in the New England Journal of Medicine. That was with single transplantation for idiopathic pulmonary fibrosis. It is from the successes and scientific inquiry of the Toronto, Barnes, Duke, and other major transplant centers that we hope to build our own program.

We did not exclude the patients undergoing single lung transplant for pulmonary hypertensive disorders for this presentation. I suspect that if we excluded that highrisk group, as well as the 16 patients who underwent bilateral transplantation for cystic fibrosis or immunerelated bronchiectasis, we might see equalization of the survival curves. We looked at the patients undergoing single or bilateral transplantation in group $\mathrm{A}$, the patients with obstructive lung disease, and we did not observe a significant difference in overall survival, with a $P$ value of .07 . That could be due to our distribution, which is weighted heavily toward single lung transplantation so that we did not have enough numbers in our bilateral group to determine any statistical significance.

Dr Keshavjee. I am also interested in your comment about bilateral thoracotomies, posterolateral thoracotomies, and 4 intraoperative deaths. How many patients had bilateral thoracotomies, and were those intraoperative deaths related to that?

Dr Chang. No, to my recollection we did not have an operative death resulting from the patients being flipped from one side to the other.

Dr Keshavjee. My last question concerns your use of intravenous cyclosporine. Do you still do that? Most people have switched to using oral cyclosporine for a number of advantages related to achieving therapeutic levels and biologic activity.

Dr Chang. We used intravenous cyclosporine in the immediate postoperative period and transitioned to oral formulation, more recently Neoral, when patients were tolerating oral intake. More recently, we have stopped using cyclosporine completely, instead using tacrolimus either sublingually or orally. Among the many reasons for which we performed this study, with the initiation of the lung allocation scoring system, we wanted to review our own prior experience for future comparison. Having done this and with the addition of a new partner to our surgical group, we found that we were holding calcineurin inhibitor therapy (intravenous cyclosporine) when patients had increased risk for postoperative renal dysfunction. Since undertaking this study we have switched over to tacrolimus, mycophenolate mofetil, as well as steroids for our posttransplant immunosuppression regimen.

Dr Frederick L. Grover (Denver, Colo). This is always an interesting topic, and I know Shaf and Alec and I go round and round about this. At Colorado we have taken the attitude of single lung transplantation for idiopathic pulmonary fibrosis and for chronic obstructive pulmonary disease in the older age groups, which generally we define as late 50 s and 60 s or 70 s, partly depending on how frail the patients are as well. We have had relatively good results with that plan. The way I always try to balance this is the shortage of organ donors and the risk of death on the waiting list versus perhaps some survival advantage and quality of life advantage on patients with double lung versus single lung transplantation. Indeed, when we were developing the scoring system for lung allocation, we tried to weigh the risk of death on the waiting list against the risk of an adverse outcome after the lung transplant itself.

Have you taken into account, if you were to do double transplants, potentially how many patients on the waiting list might not get to transplantation and what would their risk of dying be? I think you have to look at this more in the whole public health type of big picture.

Dr. Chang. Thank you for your comments, Dr Grover, and particularly for your contributions as part of the SRTR group that developed the lung allocation scoring system.

As far as how implementation of the lung allocation scoring system will affect our decisions to use bilateral transplantation, it is hard for me to predict what will happen to our waiting list mortality. Our waiting list mortality generally runs about $10 \%$ to $20 \%$, comparable to the waiting list mortality reported by Dr De Perrot. I do not know what is going to happen as far as trying to increase the number of bilateral transplants in our group further. That is a major reason why we undertook this study, to see whether we could identify factors driving our decision to proceed with either single or bilateral transplant and to establish an internal benchmark, if you will, for our future efforts.

Dr Joshua R. Sonett (New York, NY). Let me ask one question. In lieu of your data, with the new lung allocation scoring system, it appears, at least from our early experience, that it is harder for us to get lungs for even relatively sick patients with pulmonary hypertension. What was your policy, or how do you think your group would work right now? Would you still use a single transplant or would you go with doubles for the pulmonary hypertensive groups, even with the difficulty of getting organs for them?

Dr Chang. Our preference has been recently for bilateral transplants in the pulmonary arterial hypertension group, and we have observed the same thing, that their 
scores are much lower than what we would like to see given how sick they are. That is one of the reasons we hope that working with the SRTR we can potentially affect what their scoring system is set at. I do not have a good answer for that, but I think that it is important to try to better identify the sicker patients with pulmonary arterial hypertension. I have talked with our pulmonologists about this, and they send the patients to us basically when they are at death's door, and the potential of what we have is perhaps $32 \%$ mortality. I am not sure.

Dr Sonett. I think part of the problem is that nobody is able to predict ahead of time when those patients are going to fall off the tightrope that they have been walking on with the ever increasing array of medications to ameliorate the pulmonary hypertension.

Dr Chang. Right. 